\title{
VULNERABILIDADE SOCIOAMBIENTAL URBANA PELA ÓTICA DA RELAÇÃO HOMEM-NATUREZA
}

\author{
Maria Júlia Veiga da Silva ${ }^{(a)}$, Roberto Braga ${ }^{(b)}$ \\ (a) Programa de Pós-graduação em Geografia/Instituto de Geociências e Ciências Exatas, Universidade Estadual \\ Paulista, mjvsilva2000@yahoo.com.br \\ (b) Programa de Pós-graduação em Geografia/Instituto de Geociências e Ciências Exatas, Universidade Estadual \\ Paulista, rbraga@rc.unesp.br
}

\section{Eixo: Uso e Ocupação das terras e legislação ambiental.}

\begin{abstract}
Resumo
O presente artigo é uma produção teórica que procura tecer considerações sobre a relação homemnatureza no contexto da problemática ambiental tomando como conceitos norteadores da discussão a vulnerabilidade socioambiental e a produção social do espaço. Sendo assim, o objetivo deste trabalho é resgatar algumas contribuições teóricas em torno da problemática ambiental, especialmente da vulnerabilidade socioambiental, que leva em consideração a relação-homem natureza no processo de produção social do espaço. Como é um trabalho teórico teve como método de coleta de informações apenas levantamento e análise biliográfica. Ao final da construção teórica concluiu-se que é significativa a importância da relação estabelecida entre os seres humanos e os elementos da natureza, mediada pelo trabalho, para se compreender os níveis de vulnerabilidade socioambiental no contexto da estrutura espacial socialmente produzida. Há também significativa produção teórica que resgata discussões que compõem a epistemologia da geografia ao longo de sua história como ciência.
\end{abstract}

Palavras chave: natureza, sociedade, trabalho, produção social do espaço, vulnerabilidade socioambiental urbana.

\section{Introdução}

A situação atual de profunda degradação do meio natural e antrópico, tem exigido da geografia uma abordagem teórica capaz de aglomerar nas análises, tanto os elementos da natureza quanto os grupos sociais que se apropriam dos recursos naturais e produzem seu espaço de vivência nas cidades. As desigualdades que marcam geograficamente os diferentes grupos sociais estão associados à apropriação desigual dos recursos da natureza em geral e do solo urbano e que produz diferentes níveis de vulnerabilidades socioambientais.

Em sua trajetória histórica, a ciência geográfica, passou por várias transformações na definição de seu objeto e métodos de interpretação. No entanto, destaca-se aquilo que sempre esteve nas preocupações dos geógrafos, o espaço do homem. Um espaço que é produzido por meio 
da ação do homem sobre a natureza ou sobre os objetos geográficos já transformados. Importa destacar ainda o caráter interdisciplinar que orienta a análise geográfica.

Por tudo isso, é importante resgatar o projeto inicial da geografia que aglomera em sua análise a relação entre sociedade e natureza. No entanto, embora os objetos geográficos urbanos, que podem ser entendidos como uma segunda natureza, como coloca Santos (2004), muitas vezes a relação sociedade natureza fica ofuscada na análise da produção do espaço urbano. Nesse sentido, o estudo das vulnerabilidades socioambientais urbanas relacionados aos riscos naturais recoloca a discussão desta dialética no centro da análise. Então, aprofundar o conhecimento nos campos disciplinares em que se ramificou a geografia é fundamental, mas é igualmente interessante não negligenciar o teor interdisciplinar, agregador de abordagens física e humana na busca do desvendamento do espaço de vivência humana.

\section{Estudos Geográficos, Estudos Ambientais e a Relação Sociedade-Natureza: algumas considerações.}

Nas sociedades contemporâneas, a incerteza e a insegurança são condições que passaram a fazer parte do cotidiano dos diferentes grupos sociais. Os grupos estão cada vez mais expostos a perigos de diferentes tipos: naturais, sociais ou tecnológicos. O estudo sobre as vulnerabilidades socioambientais surge, assim, como uma maneira de compreender esses processos e evidenciar fatores que podem diminuir a incerteza e a insegurança quanto à possibilidade de um indivíduo, grupo, comunidade, bairro ou cidade ser afetado por um perigo. Isto significa dizer que os estudos sobre vulnerabilidades socioambientais urbanas surgem no contexto dos estudos sobre riscos e perigos e estes estudos perpassam pela compreensão da organização do espaço da cidade, ou seja, de como este vem sendo produzido, ocupado e estruturado pela população.

Dessa maneira, é importante resgatar as principais linhas de pensamento que norteiam a análise da produção do espaço na Geografia no contexto da dialética da relação sociedadenatureza, dando ênfase especial ao pensamento marxista na geografia. É igualmente necessário trazer para as considerações iniciais deste artigo a abordagem socioambiental, já que a mesma configura como expressão bastante presente neste tipo de análise. 


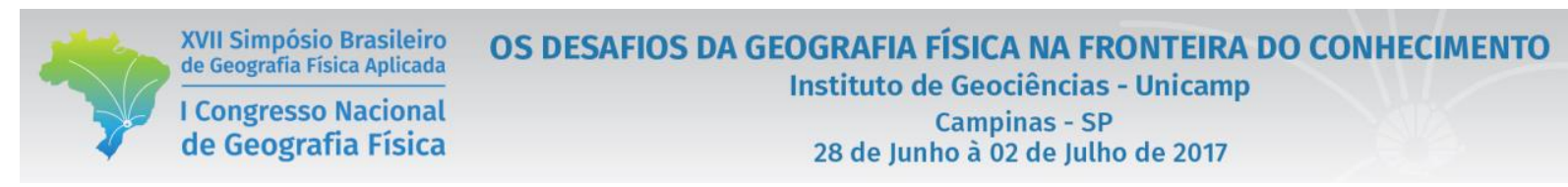

A busca por métodos específicos é inerente às ciências modernas e isso impõe um sério dilema a geografia, justamente por esta ter em seu projeto inicial e global, conforme assinala Lacoste (2012), um objeto que aglomera conjuntos e processos espaciais de ordem natural e também de ordem social. Isso gerou, em muitos casos, por vezes, o abandono da riqueza desse projeto inicial de compreender a complexa relação entre o homem e a natureza na produção do espaço. Tal projeto, conferia, e confere, à Ciência Geográfica alto teor de interdisciplinariedade. Sobre o caráter interdisciplinar na Geografia, a ser retomado sob a ótica dos estudos do ambiente, Suertegaray (2009) faz as seguintes considerações:

Estas novas formas indicam aos geógrafos a necessidade de reflexão epistemológica. Caminho árduo, mas necessário, se quisermos construir um diálogo interdisciplinar que contribua para a decifração das coisas e dos objetos ${ }^{1}$ que em interação entre si e com os homens e mulheres vivendo em sociedade, configuram a materialidade da vida. (SUERTEGARAY, 2009, p. 119).

Numa perspectiva mais ampla no contexto das ciências em geral, Lacoste (2012) também expressa o caráter interdisciplinar da geografia, assim como das demais ciências e sua relevância na compreensão da complexidade do mundo:

Evidentemente, o progresso das ciências, resulta, em grande escala, de uma divisão cada vez mais avançada do trabalho científico. Mas desde há alguns anos, ao lado das ciências sticto sensu, cada uma especializada na análise de um setor cada vez mais preciso da realidade, as reflexões epistemológicas novas legitimam o desenvolvimento de saberes científicos cuja característica e função são de combinar, de articular elementos de conhecimento que são produzidos por diferentes espécies de ciências. (LACOSTE, 2012, p. 206-207).

Lacoste (2012), Soja (1993), assim como Porto Gonçalves (2013), partindo de diferentes perspectivas de análise do espaço geográfico, propõem a superação das dicotomias que perduram no pensamento geográfico desde meados do século passado. Entre essas dicotomias, a mais destacada é aquela que separa a sociedade da natureza nas análises de parcialidades da geografia do mundo, dos países e dos lugares.

Entretanto, Mendonça (2009) destaca que apesar da necessária superação dessas dicotomias não se pode esquecer as dinâmicas próprias da natureza e da sociedade. Isso parece

1 A autora diferencia coisas de objetos, tratando o primeiro como elementos da natureza e o segundo como aqueles elementos produzidos pelos homens.

DOI - 10.20396/sbgfa.v1i2017.1859 - ISBN 978-85-85369-16-3 
pressupor a combinação de mais de um método de análise na mesma investigação científica que tenha como fim último a análise da produção social do espaço. Sobre a abordagem geográfica do ambiente e a necessidade de superação das dicotomias, Mendonça (2009) é enfático na defesa de uma "Geografia Socioambiental":

A concepção aqui adotada toma em consideração a convicção de que a abordagem geográfica do ambiente transcende a desgastada discussão da dicotomia geografia física versus geografia humana, pois concebe a unidade do conhecimento geográfico como resultante da interação entre os diferentes elementos e fatores que compõem seu objeto de estudo. (MENDONÇA, 2009, p. 123).

Moreira (2006) apresenta várias referências epistemológicas para mostrar que o aparente novo movimento teórico e metodológico vivenciado pelas ciências na atualidade, especialmente na geografia, nada mais é do que o resgate de toda a produção de embasamento filosófico abandonado e/ou não valorizado, especialmente no contexto da formação das ciências modernas em que se buscava a pureza do método como forma de dispensar caráter de cientificidade das ciências. Para a geografia a separação entre métodos das ciências da natureza e das ciências da sociedade, no contexto da modernidade, foi um duro golpe, que fez com que os jovens geógrafos abandonassem, em grande medida, o principal sentido da ciência geográfica, o seu projeto inicial que era aglomerar em sua análise tanto aspectos físicos quanto aspectos humanos. Nesse sentido, Lacoste (2012) trata como a análise de elementos inseridos nos grandes conjuntos espaciais (demográficos, geomorfológicos, do relevo, econômicas). Atualmente, as discussões em torno da problemática ambiental promovem o revigoramento da temática da relação homem-natureza na Geografia, assim como em outras ciências e inclusive ciências dedicadas aos estudos ambientais, trazendo em sua abordagem muito do que havia sido abandonado pelos primeiros geográfos modernos.

Buscando evidenciar um paradigma ambiental, Rodriguez e Silva (2016) esclarecem que o mesmo se constituiria em paradigma alternativo àquele que se elaborou no contexto das sistematização e validação das ciências modernas. Tal paradigma emerge da questão ambiental em nível mundial evidenciada na segunda metade do século XX, assim: “[...]. A questão ambiental foi se configurando como uma problematicidade, na qual prevaleceu a articulação entre os elementos da sociedade e da natureza”. (RODRIGUEZ e SILVA, 2016, p. 20). 


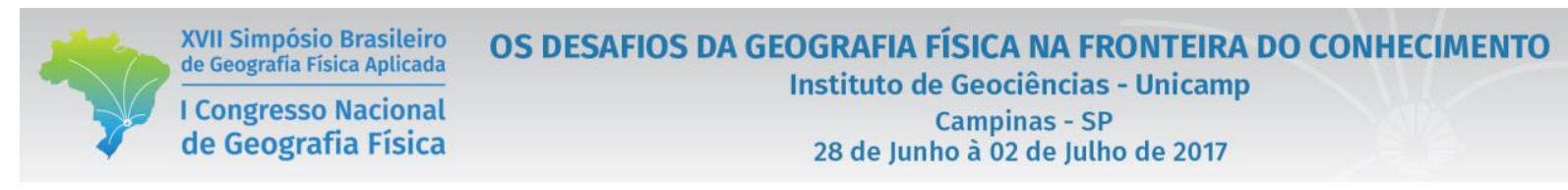

Presume-se a partir do que apresenta Rodriguez e Silva (2016) que a vertente da ciência ambiental, que se traduz na relação homem-natureza, constrói sua epistemologia segundo a própria trajetória do pensamento geográfico moderno. Para complementar tal discussão destaca-se que Suertegaray (2009) identificou, dentro da epistemologia da geografia, quatro momentos da análise da relação homem-meio:

[...]. O determinismo geográfico, onde a natureza é causa; O possibilismo geográfico onde o mundo humano constrói possibilidades técnicas de utilização da natureza; A interação dialética onde o ambiente é resultado da relação contraditória entre natureza e sociedade mediada pelo trabalho; A compreensão fenomenológica/hermenêutica, onde não há separação entre ser e ambiente. (SUERTEGARAY, 2009, p. 116).

Após apresentar um quadro sobre as principais correntes teóricas nas ciências ambientais, Rodriguez e Silva (2016) concentra-se nos principais tipos de definições de meio ambiente, sendo eles: 1. A visão biológica de Meio Ambiente; 2. Visão antropocêntrica; 3. O meio ambiente como espaço; 4. O meio ambiente como representação social; 5. O Meio ambiente na visão da ecologia humana; 6. O meio ambiente a partir de uma visão holística; 7. O meio ambiente numa visão global. Dentre as definições de meio ambiente apresentada pelos autores uma é especialmente interessante para a Geografia:

O meio ambiente como espaço: define-se o meio ambiente como um espaço com os componentes bióticos e abióticos, e socioculturais e suas interações. Aqui o ser vivo desenvolve e intercambia energia e matéria, interagindo com os diversos componentes, transformando o espaço e transformando a si mesmo (MEC, BRASIL, 1998). Considerase isto também, o resultado das inter-relações complexas de intercâmbio entre a Sociedade e a Natureza, no espaço e no tempo concretos. O meio ambiente construiu-se, de tal modo, ao longo do processo histórico de ocupação e transformação do espaço pela sociedade, surgindo como a síntese histórica das relações de intercâmbio entre a Sociedade e a Natureza (MININI MEDINA, 1994). Esta definição reflete a visão geográfica, e trata de articular-se ao espaço geográfico com a visão fatorial e biológica da relação objeto-sujeito. (RODRIGUEZ; SILVA, 2016, p. 27). (grifos nosso).

Apesar dos autores associarem o espaço a ideia de paisagem, é interessante destacar o trecho que destaca o teor metabólico da relação homem-natureza, também tratado por Moreira (2006) ao expressar o materialismo histórico e dialético na discussão da relação homem-natureza na análise geográfica.

Dessa forma, enveredar por uma análise que prime pela produção do espaço, dispensa ao pesquisador a responsabilidade de resgatar a relação dialética entre sociedade e natureza 
mediada pelo trabalho que se apresenta como uma relação metabólica entre o homem e a natureza, ou seja, uma relação que produz mudanças mútuas entre os envolvidos na relação, colocando o homem como sujeito e objeto. De acordo com o Moreira (2006), o homem como sujeito-objeto opera o salto de qualidade da história natural em história social, hominizando-se nesse processo. Moreira (2006) prossegue tecendo considerações agora sobre as esferas de interação, isto é, o homem, o trabalho e o meio ambiente.

Note-se a interação entre as três esferas, mediada agora pelo homem em sua práxis do trabalho, e o meio ambiente como um movimento de auto-regulação da natureza, de que faz parte auto-reguladora o próprio homem, e temos um terreno imenso de chão para progredir nas idéias que hoje se abrem com o retorno à superfície terrestre como objeto da geografia. (MOREIRA, 2006, p. 181).

Neste trecho retirado de Moreira (2006) duas expressões são especialmente interessantes para a orientação da análise na pesquisa aqui proposta: primeiro, o meio ambiente como um movimento de auto-regulação da natureza. Segunda expressão especialmente interessante e diretamente relacionada à primeira, é aquela que traz o retorno a superfície terrestre como o resgate do projeto inicial da investigação geográfica. Lacoste (2012) tratou desse projeto inicial como a riqueza e o diferencial da pesquisa que teria definido como sua tarefa compreender a interação de grandes conjuntos espaciais. Um projeto ambicioso que fez com que a Geografia fosse definida como ciência de síntese. Mas esse é um enfoque que dá a necessária visualização dos elementos envolvidos na produção social do espaço. Assim, o retorno à superfície terrestre como objeto da geografia possibilita a revalorização da interação entre natureza, trabalho e homem. (Moreira, 2006).

Harvey (2005b) incorpora como um dos limites da acumulação capitalista, aqueles impostos pela natureza. E não apenas a natureza natural em sua forma de recursos materiais como a natureza humana como força de trabalho. A ideia do limite biológico da força de trabalho é apresentado na obra "Espaços de esperança"; nela, Harvey (2005) discute exaustivamente as políticas do corpo e o salário vital. Segundo sua análise, dentro de uma abordagem marxista, a energia utilizada pelo homem para realizar suas atividades precisa ser reposta e, dentro de um modo de produção baseado na expropriação, não há outro meio que possa ser usufruído pelo trabalhador para a reposição de suas forças que não seja pela elevação de sua capacidade de consumo racionalizado no âmbito capitalista. Assim, há limites impostos ao capital pela natureza, seja o 
ambiente natural ou a dimensão biológica do humano. Essa perspectiva é muito válida, sobretudo quando se concebe o meio ambiente como um lugar de interação entre a materialidade (natural e antrópica) e a ação humana integrada num mundo de relações sociais de diferentes níveis de capacidade de autodeterminação.

\section{A vulnerabilidade socioambiental e os riscos e perigos ambientais.}

Para Birkmann (2006) o risco é o produto da interação entre perigo e vulnerabilidade. Assim, ele engloba a probabilidade de ocorrência de um perigo e as consequências prejudiciais ou perdas esperadas. O perigo é entendido como um evento potencialmente danoso aos sistemas naturais ou às atividades humanas e que pode causar perdas ou lesões a vidas humanas, danos às propriedades, ruptura social e econômica ou degradação ambiental. Essa análise do risco, não abdica, portanto, da análise da vulnerabilidade socioambiental, ou seja, da capacidade de lidar, exposição e sensibilidade aos perigos, sejam eles naturais, tecnológicos ou sociais.

Tanto Birkmann (2006) quanto Cutter; Boruff e Shirley (2003) apresentam e analisam o risco como a combinação de um evento perigoso, isto é, potencialmente danoso ao sistema natural e/ou as pessoas inseridas no lugar atingido pelo perigo e da vulnerabilidade, que está relacionada à capacidade de adaptação, exposição, sensibilidade e a capacidade de lidar com o perigo.

No modelo de avaliação da vulnerabilidade do lugar apresentado por Cutter; Boruff; Shirley (2003) o risco é definido como uma medida objetiva da probabilidade de ocorrência de um evento perigoso em interface com a mitigação, isto é, medidas para reduzir os riscos ou reduzir o seu impacto e o potencial de perigo. Dessa forma, o potencial do perigo pode ser moderado ou reforçado por um filtro geográfico que se refere ao local e situação do local, a proximidade, bem como o tecido social do lugar. O tecido social inclui a experiência da comunidade com os perigos, e capacidade de responder, lidar com, recuperar e adaptar-se a perigos, que por sua vez são influenciados por características econômicas, demográficas e de habitação. Assim, as vulnerabilidades sociais e biofísicas interagem para produzir a vulnerabilidade global do lugar.

A vulnerabilidade também se apresenta como a incapacidade de enfrentar os riscos ou como impossibilidade de manejar ativos para proteger-se. Baseados em fontes variadas, Marandola 


\section{OS DESAFIOS DA GEOGRAFIA FÍSICA NA FRONTEIRA DO CONHECIMENTO \\ Instituto de Geociências - Unicamp \\ Campinas - SP \\ 28 de Junho à 02 de Julho de 2017}

Jr.; Hogan (2006), apresentam algumas possibilidades de estudo e fatores relacionados a vulnerabilidade:

Os estudos demográficos da Comissión Económica para América Latina y el Caribe (Cepal), têm trabalhado também a vulnerabilidade como incapacidade de enfrentar os riscos ou como impossibilidade de manejar ativos para proteger-se (CEPAL, 2002; RODRIGUEZ, 2000). Por outro lado, capital social, humano e físico são evocados como reveladores de relações e estruturas de oportunidades que indicariam grupos populacionais mais vulneráveis (KAZTMAN, 1999; KAZTMAN; FILGUEIRA, 2006; CUNHAet al., 2006), além da importância da estrutura das famílias no enfrentamento de muitos riscos (BILAC, 2006). (MARANDOLA JR.; HOGAN, 2006, p. 36).

Ao relacionar o estudo sobre vulnerabilidades nos diversos campos do conhecimento, Marandola Jr.; Hogan (2006), destacam que nas ciências sociais incorpora-se os estudos sobre pobreza, como um conceito forte ao lado de inclusão/exclusão, marginalidade, apartheid, periferização e segregação, dependência entre outros. Mostram ainda que é na sociologia ambiental e na área de População e Ambiente que a problemática ambiental, relacionada aos riscos e perigos, é reconhecida como uma das consequências da dinâmica e da estrutura social. Dessa forma:

[...] Os riscos e perigos ambientais passam a ser considerados como produtos do sistema, intrincados na trama social e fruto da modernização ecológica, da modernidade tardia e de processos de segregação e desigualdade social. [...]. (MARANDOLA JR.; HOGAN, 2006, p. 36).

Para Acselrad (2006) a vulnerabilização é o processo que gera a vulnerabilidade. Tal processo se desenvolve no contexto socioeconômico e sociopolítico que promovem a distribuição desigual de equipamentos, ou seja, estaria relacionado a decisões de natureza distributiva. Dessa forma, a vulnerabilidade é socialmente produzida, mesmo os diferentes níveis de vulnerabilidade socioambiental.

As decisões políticas são espacializadas. Tais decisões se dão no contexto dos modelos decisórios dentre os quais está o modelo democrático. Vale ressaltar que a política é uma das dimensões analisadas no processo de produção do espaço, conforme destacado por Barrios (1978). Interessa determinar e assim interromper os processos decisórios que impõem riscos aos mais desprotegidos - decisões para alocação de equipamentos danosos e dinâmicas inigualitárias do mercado de terras, isto é: 


\section{OS DESAFIOS DA GEOGRAFIA FÍSICA NA FRONTEIRA DO CONHECIMENTO \\ Instituto de Geociências - Unicamp \\ Campinas - SP \\ 28 de Junho à 02 de Julho de 2017}

Fatores com ação diferenciada concorrem para a maior ou menor exposição ao agravo ou a maior ou menor chance de proteção contra ele. Isto porque há mecanismos de distribuição desigual de tal proteção. Estes fatores são objetivos, sim: uns têm o poder de se proteger, de se tornarem menos vulneráveis - via mobilidade espacial, influência nos processos decisórios, controle do mercado das localizações etc., enquanto que outros terão sua mobilidade restrita aos circuitos da vulnerabilidade - de debaixo de um viaduto para cima de um oleoduto etc... Mas há também fatores subjetivos - ocorrem diferentes concepções do que seja tolerável ou intolerável numa dada condição de existência. A condição de vulnerabilidade é, pois, socialmente construída. (ACSELRAD, 2006, p. 2$3)$.

Acselrad (2006) ainda destaca que na expressão dos mecanismos relacionados à vulnerabilidade, algumas formas de ver a realidade social podem ofuscar a percepção dos fatores que produzem a vulnerabilidade, destacando, assim, a sociologia da recusa e do consentimento na visualização das condições de vulnerabilidade. A falta de questionamento quanto a sua própria condição se refere ao consentimento. Pois que a vulnerabilidade é uma relação e não uma carência. “Consideradas, pois, as relações e contextos, há diferentes 'vulnerabilidades', diferentes situações e condições que se articulam nos distintos momentos e localizações.” (ACSELRAD, 2006, p. 5). Então é preciso estabelecer a dimensão societal da vulnerabilização caracterizando os processos envolvidos para os fins de sua posterior interrupção.

Herculano (2002), em artigo pioneiro na discussão sobre a relação entre riscos ambientais e injustiça ambiental no Brasil, alerta que o conceito de "sociedade de riscos" pode ofuscar a percepção de que o risco ambiental não é tão democrático quanto se acredita ser. Essa autora considera que esse conceito mascara a percepção de que o risco é desigualmente distribuído na sociaedade, sendo diferentemente potencializado conforme a situação socioeconômica do indivíduo ou coletividade afetada. Isso implica que determinado perigo natural ou, ainda, a distribuição dos riscos tecnológicos varie conforme a distribuição espacial das classes sociais.

[...] o conceito obscurece o fato de que as hierarquias continuam e se acentuam e de que, pelo menos por enquanto, os riscos ambientais têm limites e são sofridos pelos mais pobres, pelas classes subalternas. E, justamente porque são empurrados para os mais vulneráveis, tornam-se insolúveis, invisíveis, mas crescentes. (HERCULANO, 2002, p. 2).

Dessa forma, a produção social do espaço não só pode ser incorporada nos estudos sobre riscos e vulnerabilidades socioambientais na pesquisa geográfica e nas políticas ambientais e urbanas das instâncias de governo como também na instrumentalização dessas mesmas políticas 
através da compreensão da totalidade social espacializada por meio das práticas econômicas, políticas e culturais.

Marandola Jr. \& Hogan (2006) apontaram que, no Brasil, os estudos sobre áreas de risco se conformam, basicamente, em duas abordagens. A primeira leva em consideração um conjunto de fatores naturais que expressam a fragilidade do sistema natural de uma determinada área a um evento perigoso seja ele de origem natural ou antrópica. A segunda, que não está isolada da primeira, considera as restrições a habitabilidade em função dos riscos de ocorrências de eventos perigosos que possam causar danos, perdas de vidas humanas e materiais, ou seja, trata-se de áreas que apresentam significativa exposição a um evento perigoso, seja ele de origem natural, tecnológico ou social, produzindo, assim, incompatibilidade com a presença humana. E dependendo da probabilidade de ocorrência do evento perigoso, no caso de já existir a presença humana, recomenda-se a remoção das pessoas ou a gestão do risco.

De acordo com Marandola Jr.; Hogan (2006) que os estudos sobre vulnerabilidades devem ser orientados a partir de questionamentos, sendo os principais: Vulnerabilidade a que? Ou seja, a vulnerabilidade sempre será definida a partir de um perigo ou um conjunto deles em dado contexto geográfico e social; onde e quem é ou está vulnerável? Estes questionamentos levam a delimitações que possibilitam identificar os fatores que podem promover a diminuição da vulnerabilidade, bem como as situações ou elementos que aumentam o risco. (MARANDOLA JR.; HOGAN, 2006).

[...] o profundo conhecimento do perigo (o evento) e dos processos envolvidos no contexto social e geográfico, colocados numa escala adequada para a sua apreensão, é vital para que as estruturas que configuram a vulnerabilidade possam ser elucidadas e compreendidas de forma contextual. (MARANDOLA JR.; HOGAN, 2006, p. 37).

Assim, um estudo consistente de avaliação da vulnerabilidade socioambiental deve considerar o quadro sobre o contexto social e geográfico e o perigo associado ao grupo delimitado espacial e temporalmente.

[...] Uma avaliação da vulnerabilidade passa pela compreensão do perigo envolvido (eventos que causam danos), do contexto geográfico e da produção social (as relações sociais, culturais, políticas, econômicas e a situação das instituições), que revelarão os elementos constituintes da capacidade de resposta, absorção e ajustamento que aquela sociedade ou lugar possuem para enfrentar o perigo. (MARANDOLA JR.; HOGAN, 2006, p. 35). 
Portanto, o quadro social e geográfico associado à um perigo natural ou tecnológico é que vai dar os elementos para a avaliação da vulnerabilidade socioambiental em dada unidade espacial. Dessa maneira, os estudos sobre vulnerabilidades socioambientais urbanas não podem prescindir de uma profunda análise da estrutura social e da própria estrutura espacial urbana e da apropriação desigual de recursos ambientais e de equipamentos e serviços urbanos, uma vez que a vulnerabilidade, assim, como os riscos ambientais e o espaço geográfico são socialmente produzidos.

\section{Considerações Finais}

Os estudos em torno da problemática ambiental contemporânea, especialmente no espaço urbano, sugere a retomada e valorização da dialética da relação homem-natureza. Tal relação, mediada pelo trabalho e pela relação social entre os seres humanos, conduz à investigação sobre a produção social do espaço para se compreender como se dá construção social do risco e dos níveis de vulnerabilidade socioambiental.

A cidade, por se tratar de um espaço bastante transformado, exige aprofundada análise da produção do espaço, resgatando diferentes escalas espaciais e temporais. A identificação do papel dos recursos ambientais na problemática socioambiental urbana, e sua relação com os diferentes níveis de vulnerabilidade é algo que a geografia tem grande contribuição a dar e já se observam diversos estudos que apontam nessa direção.

\section{Bibliografia}

ACSELRAD, H. Vulnerabilidade ambiental, processos e relações. Comunicação ao II Encontro de produtores de informações sociais, econômicas e territoriais. FIBGE, Rio de Janeiro, 24/08/2006.

BIRKMANN, J. Measuring vulnerability to promote disaster-resilient societies: conceptual frameworks and definitions. In: BIRKMANN, J (ed.) Measuring vulnerability to natural hazards: towards disaster resilient societies. New Deli, India: Teri Press, 2006.

CUTTER, S. L.; BORUFF, B. J.; SHIRLEY, W. L. Social Vulnerability to Environmental Hazards. Social science quarterly, volume 84, number 2, june, 2003.

HARVEY, D. Espaços de esperança. São Paulo: Edições Loyola, 2005.

. A produção capitalista do espaço. São Paulo: Annablume, 2005 b.

DOI - 10.20396/sbgfa.v1i2017.1859 - ISBN 978-85-85369-16-3 


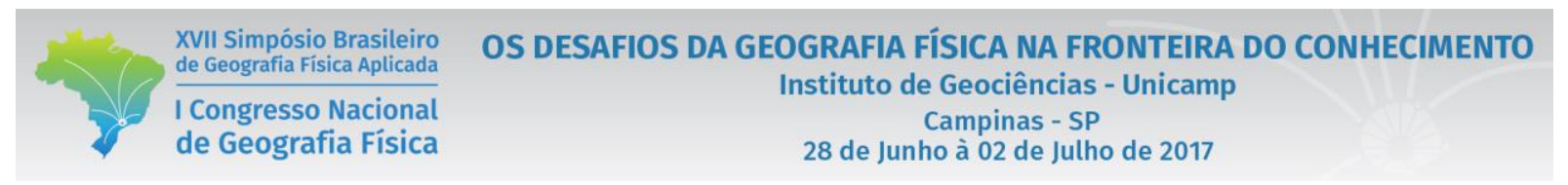

HERCULANO, S. Riscos e desigualdade social: a temática da Justiça Ambiental e sua construção no Brasil. In: I ENCONTRO DA ANPPAS, 2002, Indaiatuba/SP. Anais. Indaiatuba: ANPPAS, 2002.

LACOSTE, Y. A geografia, isso serve em primeiro lugar, para fazer a guerra. 19a edição. São Paulo: Papirus, 2012.

MARANDOLA JR., E; HOGAN, D. J. As dimensões da vulnerabilidade. São Paulo em perspectiva, v. 20, n. 1, p. 33-43, jan./mar., 2006.

MENDONÇA, F. de A. \& LEITÃO, S. A. M. Riscos e vulnerabilidade socioambiental urbana: uma perspectiva a partir dos recursos hídricos. Geotextos, vol. 4, n. 1 e 2, 2008 (p. 145-167).

MENDONÇA. F. Geografia socioambiental. In: MENDONÇA, F.; KOZEL, S. (Orgs.). Elementos de epistemologia da Geografia contemporânea. $1^{a}$ edição revisada. Curitiba: Editora da UFPR, 2009. (p. 121 a 144).

MOREIRA, R. Marxismo e geografia: a geograficidade e o diálogo das ontologias. In: Geographie. Ano 6. No 11, 2004. (p. 21 a 37).

Para onde vai o pensamento geográfico? Por uma epistemologia crítica. São Paulo: Contexto, 2006.

PORTO GONÇALVES, C. W. A globalização da natureza e a natureza da globalização. $5^{\text {a }}$ edição. Rio de Janeiro: Civilização brasileira, 2013.

RODRIGUES, A. M. A matriz discursiva sobre "meio ambiente": produção do espaço urbano - agentes, escalas, conflitos. In: CARLOS, A. F. A; SOUZA, M. L. de; SPOSITO, M. E. B. (Orgs.). A produção do espaço urbano: agentes e processos, escalas e desafios. São Paulo: Ed. Contexto, 2011. (p. 207 a 230).

RODRIGUEZ, J. M. M.; SILVA, E. V. Educação ambiental e desenvolvimento sustentável. $4^{a}$ edição. Reimpressão. Fortaleza: Expressão gráfica e editora, 2016.

Por uma geografia nova. São Paulo: EDUSP, 2004. (Coleção Milton Santos; 2).

SOJA, E. W. Geografias pós-modernas: a reafirmação do espaço na teoria social crítica. Rio de Janeiro: Jorge Zahar Editor, 1993.

SUERTEGARAY, D. M. A. Geografia física (?) geografia ambiental (?) ou geografia e ambiente. In: MENDONÇA, F.; KOZEL, S. (Orgs.). Elementos de epistemologia da Geografia contemporânea. 1 ${ }^{\text {a }}$ edição revisada. Curitiba: Editora da UFPR, 2009. (p. 111 a 120). 